\title{
Clustering Kualitas Kinerja Karyawan Pada Perusahaan Bahan Kimia Menggunakan Algoritma K-Means
}

\author{
Sandra Regina ${ }^{1}$, Entin Sutinah ${ }^{2, *}$, Nani Agustina ${ }^{3}$ \\ ${ }^{1}$ Program Studi Sistem Informasi, STMIK Nusa Mandiri, DKI Jakarta, Indonesia \\ ${ }^{2}$ Fakultas Teknik dan Informatika, Prodi Sistem Informasi, Universitas Bina Sarana Informatika, DKI Jakarta, Indonesia \\ ${ }^{3}$ Fakultas Teknik dan Informatika, Prodi Sistem Informasi Akuntansi, Universitas Bina Sarana Informatika, DKI Jakarta, \\ Indonesia \\ Email: ${ }^{1}$ sandrareginalatu@gmail.com, 2,*entin.esh@bsi.ac.id, ${ }^{3}$,nani.nna@bsi.ac.id \\ Email Penulis Korespondensi: entin.esh@bsi.ac.id
}

\begin{abstract}
Abstrak-Penilaian kualitas kinerja karyawan merupakan salah satu hal penting dan sangat dibutuhkan oleh perusahaan, namun pada PT Clariant Adsorbents Indonesia saat ini belum memiliki sistem penilaian kualitas kinerja karyawan. Penelitian ini bertujuan untuk mengetahui produktifitas seorang karyawan dan keefektifan kinerja seorang karyawan dimasa yang akan datang. Penilaian kinerja karyawan ini dibagi menjadi beberapa cluster yaitu sangat produktif, cukup produktif dan kurang produktif serta metode yang digunakan pada penelitian ini adalah metode K-means, dimana metode k-means merupakan metode yang paling popular pada algoritma clustering. Metode k-means mencari beberpa partisi yang paling optimal dari data yang diolah dengan cara meminimalisir kesalahan dari kriteria menggunakan iterasi yang optimal. Variabel yang digunakan terdiri dari nama karyawan, nilai kualitas pekerjaan, nilai tanggung jawab, nilai kerjasama, nilai kehadiran serta nilai kedisiplinan. Penelitian ini dalam mengolah data nya menggunakan Rapidminer Versi 7.6.0.0.1 menggunakan metode Kmeans. Hasil akhir dari penelitian ini untuk mendapatkan pengelompokan dari penilaian menjadi beberapa kategori yaitu sangat produktif, cukup produktif dan kurang produktif dan hasil pengelompokan 0,42\% untuk cluster 1 kategori sangat produktif, yang terdiri dari 16 data karyawan, $0,47 \%$ untuk cluster 2 kategori cukup produktif, yang terdiri dari 18 data karyawan, $0,11 \%$ untuk cluster 3 kategori kurang produktif, yang terdiri dari 4 data karyawan.
\end{abstract}

Kata Kunci: Algoritma K-Means, Clustering, Kualitas Kinerja Karyawan

\begin{abstract}
Assessment of the quality of employee performance is one of the important things and is very much needed by the company, however, PT Clariant Adsorbents Indonesia does not currently have an employee performance quality system. This study aims to see the productivity of an employee and the effectiveness of an employee's performance in the future. Employee performance appraisal is divided into several clusters that are highly productive, moderately productive and less productive. The method used in this study is the K-means method, where the k-means method is the most popular method in the clustering algorithm. The k-means method looks for some of the most optimal partitions of the processed data by minimizing the error of the criteria using the optimal iteration. The variables used consist of employee names, work quality scores, responsibility values, cooperation values, attendance values, and discipline values. This research in processing data using Rapidminer Version 7.6.0.0.1 using the K-means method. The final result of this research is to get the grouping of the assessment into several categories that are very productive, quite productive and less productive and the clustering results are $0.42 \%$ for cluster 1 , very productive category, which consists of 16 employee data, $0.47 \%$ for cluster 2 quite productive category, which consists of 18 employee data, $0.11 \%$ for cluster 3 , less productive category, which consists of 4 employee data.
\end{abstract}

Keywords: K-Means Algorithm; Clustering; Quality of Employee Performance

\section{PENDAHULUAN}

Bagi sebuah perusahaan sumber daya manusia menjadi bagian yang sangat penting. Tugas manajemen melakukan kegiatan melakukan penilaian kinerja (performance appraisal) karyawannya. Setiap perusahaan mengharapkan karyawan yang memiliki kinerja sesuai dengan standart perusahaan bahkan lebih dari yang diharapkan perusahaan [1]. Penilaian kinerja (performance appraisal) menjadi kegiatan yang penting untuk menentukan apakah seorang karyawan dapat melakukan tugas yang diberikan sesuai dengan tanggung jawab yang diberikan oleh perusahaan dimana kenyataannya sistem penilaian kualitas kinerja karyawan sangat dibutuhkan oleh perusahaan [2] Kinerja merupakan hasil kerja secara kualitas dan kuantitas dicapai oleh seorang karyawan dalam melaksanakan tugasnya sesuai dengan taggung jawab yang diberikan kepadanya untuk dikerjakan sesuai dengan kebutuhan [3]. Karyawan adalah orang yang asing bagi usaha kita, mereka masuk ke perusahaan dengan tujuan untuk bekerja, dan tidak mengetahui visi dan misi dari perusahaan yang dapat dibaca dan di mengerti para karyawan kita, maka mereka hanya akan bekerja menuruti perintah kita saja tanpa pernah berusaha kerja untuk mencapai tujuan sebenarnya yang kita inginkan [4]. Karyawan bagian dari aset berharga untuk menjaga kesejahteraan dan kepuasan sebagai seorang karyawan karena sebuah perusahaan meskipun memiliki sarana dan prasarana yang baik belum tentu bisa berjalan dengan baik tanpa adanya karyawan yang cakap dalam bekerja dan memiliki motivasi kerja yang baik [5]. Kebingungan dimiliki perusahaan apabila akan melakukan penilaian kemampuan karyawan pada setiap bagian dikarenakan kebutuhan, dengan banyak jumlah pegawai yang ada diperusahaan, penilaian tentang kemampuan seseorang perusahaan sangat dibutuhkan agar dapat mengetahui kinerja sari seorang karyawan. Data mining sangat cocok untuk mengatasi masalah yang terjadi untuk mengolah nilai kemampuan pegawai [6].

Beberapa Penelitian terkait sebelumnya yang menggunakan algoritma K-Means diantaranya perusahaan akan terus berkembang memiliki kemapuan yang beragam dan perusahaan tentunya membutuhkan data perkembangan dari para pegawainya untuk mendukung kinerja yang dibutuhkan, agar mengetahui dengan mudah 
dan cepat dalam mengetahui kemampuan tiap pegawai, maka bisa menggunakan data mining dengan algoritma $\mathrm{K}$ Means Clustering yang mengelompokan data kemampuan berdasarkan nilai dalam bidang IT sehingga akan mempermudah dalam melihat kemampuan baru dalam perusahaan tersebut [6]

Salah satu perguruan tinggi swasta yang memiliki potensi menjadi perguruan tinggu terkemuka dikota Bandung salah satunya STT Bandung. Evaluasi kinerja karyawan yakni dengan pemantauan kedisiplinan karyawan maka diperlukan Teknik data mining untuk klastering data dengan menggunakan metode K-Means dengan membagi kinerja karyawan menjadi 3 kluster, yaitu dimulai dari tingkat kinaeja tinggi, tingkat kinerja sedang dan tingkat kinerja rendah [7].

Pengelompokan data daftar program SDP tahun 2017 untuk mengetahui manakah pegawai yang layak lolos agar dapat melalukan Registrasi Asessment Center, pada penelitian ini melakukan pengelompokan seperti kedisiplinan pegawai, target kerja pegawai, kepatuhan program SDP pemililihan kriteria agar dihasilkan pengelompokan lebih optimal [8]

PT Clariant Adsorbent Indonesia belum terdapat sistem penilaian kualitas kinerja karyawan. Dalam kasus ini proses penilaian kualitas kinerja karyawan melibatkan manajer, karyawan dan ahli sumber daya manusia HRD (Human Resource Departement) dalam pengambilan keputusan. Penilaian sistem dilakukan dengan pengisian kuesioner yang disebar yang berisi kriteria yang digunakan dalam penilaian. Terdapat masalah dalam penilaian seperti ini misalnya butuhnya biaya untuk mencetak kuestioner dan butuh waktu untuk melakukan penyebaran questioner yang dianggap kurang efisien dan efektif. Dari sisi penilaian juga kurang objektif dikarenakan pengisian berdasarkan hati dan kedeketan karyawan sehingga nilai yang didapat memiliki kemiripan sehingga sulit untuk menentukan yang unggul. Berdasarkan masalah tersebut, maka masalah tersebut dapat diterapkan dengan metode clustering [9], serta untuk memudahkan pihak manajemen dalam mengelompokan kinerja serta kedisiplian setiap karyawan maka teknik clustering sangatlah diperlukan [7].

Clustering bagian dari suatu metode data mining yang bersifat tanpa arahan (unsupervised) dan suatu metode untuk mencari dan mengelompokan data yang memiliki kemiripan secara karakteristik dengan membandingkan satu data dengan data lain. Data Mining adalah proses yang memperkejakan satu atau lebih teknik pembelajaran computer (Machine Learning) untuk menganalisis dan mengekstraksi pengetahuan (Knowledge) secara otomatis. Knoeledge Discovery in Databases (KDD) adalah penerapan metode saintifik pada data mining [10].Clustering banyak digunakan di berbagai bidang seperti biologi, psikologi, dan ekonomi. Hasil dari pengelompokan bervariasi dikarenakan jumlah perubahan yang terdapat dalam parameter cluster maka tujuan utama analisis cluster adalah total cluster atau total dari parameter model yang jarang diketahui, hal ini harus ditentukan sebelum pengelompokan. Pada tahap clustering terdiri dari beberapa algoritma pengelompokan untuk mempermudah dalam mengelompokan data[11].

Algoritma K-Means metode analisis kelompok mengarah partisian $\mathrm{N}$ objek penelitian ke dalam $\mathrm{K}$ kelompok, di mana setiap objek yang akan diamati dalam sebuah kelompok data dengan mean (rata-rata) yang saling berdekatan [8]. K dimaksudkan sebagai konstanta total cluster yang diinginkan, Means disini diambil dari nilai suatu rata-rata dari suatu grup data yang dalam hal ini sebagai cluster, sehingga Kmeans Clustering adalah suatu metode analisa data atau metode data mining salah satu metode yang melakukan pengelompokan data dengan sistem partisi [12]. K-means clustering mengelompokkan data dengan memaksimalkan kemiripan data antar cluster dan meminimalkan kemiripan data antar cluster, dan yang memiliki karakteristik yang berbeda akan dikelompokkan dalam cluster lain yang memiliki ciri sama, dimana yang menjadi ukuran kemiripan yang akan digunakan dalam cluster fungsi jarak, sehingga kemiripan data didapatkan berdasarkan jarak terpendek antara data terhadap titik pusat [13]. Algoritma k-means merupakan algoritma clustering yang berulang-ulang. Algoritma $k$-means ditentukan dengan tahapan menilai clustering $(\mathrm{K})$ dengan cara random, dan nilai yang didapat sementara menjadi pusat dari clustering atau centroid, mean, atau "means"[14]. Pada ilmu statistik dan mesin pembelajaran metode k-menas merupakan sebuah metode pemartisian data objek pengamatan kedalam Kelompok dan setiap pengamatan kelompok dimiliki oleh kelompok dengan means terdekat, lalu keduanya mencoba menemukan pusat dari kelompok yang terbentuk sebanyak iterasi yang dilakukan oleh algoritma tersebut [15].

Metode K-Means dapat mempermudah bagi pihak perusahaan dalam melakukan analisa dan pengelompokan data untuk mengetahui kemampuan dari setiap karyawan, dalam pengelompokan dibagi menjadi beberapa kategori berdasarkan nilai tanggung jawab, disiplin, kerjasama, kualitas pekerjaan dan kehadiran melalui data nilai karyawan yang berjumlah besar, analisa data mining dilakukan dengan teknik clustering yang menggunakan algoritma K-means diharapkan dapat memberikan kontribusi yang baik dalam pengelompokan kualitas kinerja karyawan dan perusahaan dapat menerapaknya. Pada penilaian kinerja karyawan juga diharapkan dapat mempersingkat waktu dalam mengambil keputusan serta lebih objectif.

\section{METODOLOGI PENELITIAN}

\subsection{Tahapan Penelitian}

Analisis Data merupakan bagian dari tahap penelitian yang sistematis untuk membantu penelitian menjadi terarah dengan baik. Berikut adalah metedologi penelitian yang dilakukan penulis. 


\section{Identifikasi pemasalahan}

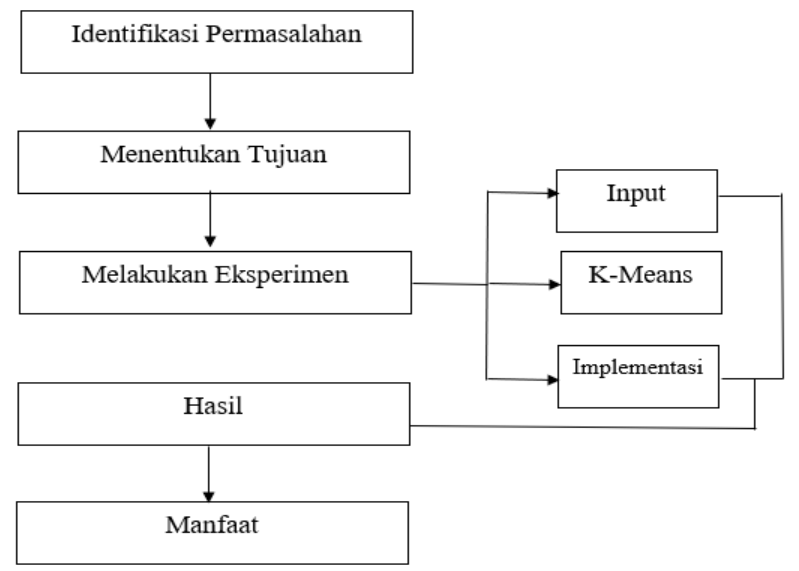

Gambar 1. Bagian Analisis Data [2]

Pada tahap penelitian ini menjelaskan segala permasalahan yang ada pada perusahaan berdasarkan dari hasil pengamatan langsung dan wawancara.

\section{Menentukan tujuan}

Pada tahapan ini penulis menentukan tujuan dimana tujuan dari penelitian ini adalah mengetahui tingkat produktif karyawan PT Clariant Adsorbents Indonesia dan mengelompokan data karyawan berdasarkan kualitas kinerja dari karyawan tersebut.

\section{Melakukan Eksperimen}

Pada tahapan ini dilakukan input data terlebih dahulu lalu di proses dengan menggunakan metode k_Means, setelah didapat hasilnya langkah selanjutnya memberikan usulan ke perusahaan untuk dilakukan implementasi.

Hasil

Pada tahapan penilitian ini menentukan hasil yang dicapai setelah dilakukannya tahap eksperimen

Manfaat

Pada tahapan ini dapat dilahiat seberapa besar manfaat yang dirasakan berdasarkan dari hasil penelitian

Populasi pada penelitian ini diambil dari sebuah laporan data karyawan pada bagian produksi pada PT. Clariant Adsorbents Indonesia sebanyak 61 orang pada tahun 2020. Maka dari itu penelitian ini menggunakan sampel yang berasal dari populasi tersebut [16]. Dalam menentukan jumlah sampel pada penelitian ini menggunakan rumus Slovin [17].

$$
n=\frac{N}{1+N e^{2}}
$$

Dimana:

$\mathrm{n}$ : Jumlah Sampel

$\mathrm{N}$ : Jumlah Populasi

e : Batas Toleransi Kesalahan (Error Tolerance)

Untuk menggunakan rumus ini, tentukan terlebih dahulu berapa batas toleransi kesalahan yang akan digunakan. Batas toleransi kesalahan ini dinyatakan dengan persentase. Semakin kecil toleransi kesalahan yang digunakan maka semakin akurat sampel yang mengambarkan dari populasi. Penelitian ini mengunakan batas kesalahan 10\% memiliki tingkat akurasi $90 \%$. Dengan menggunakan populasi yang sama pada penelitian ini maka hasilnya semakin kecil toleransi kesalahan, maka semakin besar juga jumlah sampel yang dibutuhkan.

Sampel dalam penelitian ini adalah laporan data karyawan pada PT. Clariant Adsorbents Indonesia pada tahun 2020 dengan jumlah populasi sebanyak 61 dan persentasi akurasi sebesar $90 \%$ atau sig. $=0,1$ maka jumlah sampel yang diambil dapat dihitung sebagai berikut :

$\mathrm{n}=\mathrm{N} /(1+\mathrm{N} . \mathrm{e} 2)$

$\mathrm{n}=61 /(1+61 .(0,1) 2)$

$\mathrm{n}=61 / 1,61$

$\mathrm{n}=37,888(38)$

Hasil dari pengolahan data populasi diatas dapat disimpulkan bahwa jumlah sampel pada penelitian ini adalah berjumlah 38 data karyawan .

Hasil dari pengolahan data populasi diatas dapat disimpulkan bahwa jumlah sampel pada penelitian ini adalah berjumlah 38 data karyawan .

Tabel 1. Sampel Penelitian

\begin{tabular}{cc}
\hline Usia & Jumlah \\
\hline $20-30$ & 22 \\
$31-41$ & 10
\end{tabular}




\begin{tabular}{cc}
\hline Usia & Jumlah \\
\hline $42-$ & 6 \\
55 & \\
\hline
\end{tabular}

\subsection{Instrumen Penelitian}

Instrumen Penelitian merupakan sebuah alat atau fasilitas yang dapat digunakan oleh para peneliti untuk mengumpulkan data supaya perkerjaan lebih mudah untuk dilakukan, serta menghasilkan sebuah hasil penelitian yang lebih baik, cermat, lengkap, dan sistematis [17].

Dalam melakukan penelitian penulis membutuhkan instrumen untuk dapat membantu penulisan. instrumen penelitaian yang digunakan:

1. Data Primer

Data ataupun informasi penelitian ini diperoleh dari perusahaan tersebut, data penilaian kinerja karyawan pada tahun 2020 sebanyak 61 data pada PT. Clariant Adsorbents Indonesia yang digunakan untuk menentukan tingkat produktif kinerja karyawan berdasarkan nilai tanggung jawab, disiplin, kerjasama, kualitas pekerjaan dan kehadiran.

2. Hardware

Kebutuhan perangkat keras (Hardware) yang digunakan :

a. Laptop Asus Inter® Celeron® CPU N2840 @ 2.16GHz $2.16 \mathrm{GHz}$

b. RAM 2.00GB

3. Software

Kebutuhan perangkat lunak(software) yang digunakan :

a. Sistem operasi Windows 8

b. Microsoft Excel 2013 sebagai pengolahan data

c. Aplikasi RapidMiner Studio Versi 7.6.0.0.1 sebagai implementasi data

\subsection{Metode Analisi Data}

Penelitian ini dilakukan pada PT. Clariant Adsorbents Indonesia. Dalam pengolahan data, penulis menggunakan metode clustering dengan algoritma $\mathrm{K}$-Means untuk melakukan perhitungan pada data penilaian karyawan.

1. Menghitung Jarak Terdekat

Untuk menghitung jarak terdekat, pada penelitian ini digunakan $L_{2}$ (Euclidian) distance space, jarak antara dua titik hitung dengan rumus sebagai berikut:

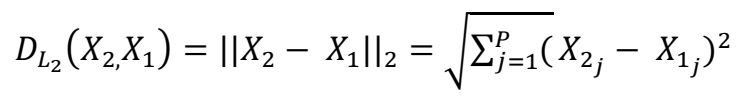

Dimana $p$ merupakan dimensi data, adapun data $p$ di sini berjumlah 5 yaitu sesuai dengan variabel yang digunakan sebanyak 5 .

2. Pengukuran Nilai Akurasi(Accuration Rate)

$$
\text { Accuration Rate }=\frac{\text { Jumlah data yang sesuai label aslinya }}{\text { Jumlah data keseluruhan }} \times 100 \%
$$

\section{HASIL DAN PEMBAHASAN}

Dalam penilaian kualitas kinerja karyawan pada PT. Clariant Adsorbents Indonesia saat ini belum terdapat sistem penilaian kualitas kinerja karyawan, selama ini pihak perusahaan hanya mengacu pada form lembar penilaian kinerja karyawan dalam melakukan penilaian. Namun pada lain sisi penilaian kualitas kinerja karyawan juga sangat penting bagi suatu perusahaan untuk mengetahui sejauh mana tingkat produktif para karyawan. Maka dari itu penulis melakukan penelitian dalam pengelompokan variabel yang berpengaruh terhadap penilaian kualitas kinerja karyawan. Dalam penelitian ini penulis melakukan pengelompokan dengan menggunakan 5 variabel, yaitu:

Tabel 2. Variabel Perhitungan

\begin{tabular}{c}
\hline Variabel \\
\hline Kualitas Pekerjaan \\
Tanggung Jawab \\
Kerjasama \\
Kehadiaran \\
Disiplin \\
\hline
\end{tabular}

Di bawah ini adalah 38 data penilaian kualitas kinerja karyawan pada PT. Clariant Adsorbents Indonesia pada tahun 2020. Data dikelompokan berdasarkan variabel-variabel yang ada pada penilaian kinerja karyawan. 
JURNAL MEDIA INFORMATIKA BUDIDARMA

Volume 5, Nomor 2, April 2021, Page 573-582

ISSN 2614-5278 (media cetak), ISSN 2548-8368 (media online)

Available Online at https://ejurnal.stmik-budidarma.ac.id/index.php/mib DOI 10.30865/mib.v5i2.2909

Tabel 3. Data Penelitian Kualitas kinerja karyawan

\begin{tabular}{|c|c|c|c|c|c|c|}
\hline \multirow{2}{*}{ No } & \multirow{2}{*}{ Karyawan } & \multicolumn{5}{|c|}{ Faktor Penilaian } \\
\hline & & $P 1$ & $P 2$ & $P 3$ & P4 & P5 \\
\hline 1 & K1 & 3 & 2 & 2 & 4 & 3 \\
\hline 2 & $\mathrm{~K} 2$ & 3 & 3 & 2 & 4 & 3 \\
\hline 3 & K3 & 3 & 2 & 2 & 3 & 3 \\
\hline 4 & $\mathrm{~K} 4$ & 3 & 2 & 2 & 4 & 3 \\
\hline 5 & K5 & 2 & 2 & 2 & 2 & 3 \\
\hline 6 & K6 & 2 & 2 & 2 & 4 & 4 \\
\hline 7 & $\mathrm{~K} 7$ & 2 & 2 & 2 & 4 & 4 \\
\hline 8 & K8 & 2 & 2 & 2 & 4 & 3 \\
\hline 9 & K9 & 2 & 2 & 2 & 2 & 2 \\
\hline 10 & K10 & 4 & 3 & 3 & 2 & 5 \\
\hline 11 & K11 & 2 & 2 & 2 & 3 & 2 \\
\hline 12 & K12 & 2 & 2 & 2 & 3 & 5 \\
\hline 13 & K13 & 3 & 2 & 2 & 4 & 2 \\
\hline 14 & K14 & 4 & 2 & 2 & 3 & 2 \\
\hline 15 & K15 & 2 & 2 & 2 & 3 & 2 \\
\hline 16 & K16 & 4 & 4 & 3 & 4 & 4 \\
\hline 17 & K17 & 2 & 2 & 2 & 2 & 2 \\
\hline 18 & K18 & 2 & 2 & 2 & 3 & 4 \\
\hline 19 & K19 & 2 & 2 & 2 & 2 & 1 \\
\hline 20 & K20 & 1 & 2 & 2 & 3 & 3 \\
\hline 21 & K21 & 2 & 3 & 1 & 5 & 2 \\
\hline 22 & $\mathrm{~K} 22$ & 2 & 2 & 2 & 2 & 2 \\
\hline 23 & K23 & 3 & 2 & 2 & 2 & 2 \\
\hline 24 & K24 & 4 & 3 & 2 & 4 & 2 \\
\hline 25 & $\mathrm{~K} 25$ & 3 & 3 & 3 & 2 & 3 \\
\hline 26 & K26 & 2 & 2 & 3 & 2 & 4 \\
\hline 27 & K27 & 2 & 4 & 3 & 2 & 2 \\
\hline 28 & K28 & 1 & 4 & 3 & 2 & 2 \\
\hline 29 & K29 & 3 & 2 & 2 & 4 & 5 \\
\hline 30 & K30 & 4 & 2 & 3 & 2 & 3 \\
\hline 31 & K31 & 4 & 2 & 2 & 2 & 2 \\
\hline 32 & K32 & 5 & 2 & 2 & 2 & 2 \\
\hline 33 & K33 & 3 & 2 & 3 & 2 & 3 \\
\hline 34 & K34 & 3 & 2 & 2 & 3 & 3 \\
\hline 35 & K35 & 4 & 4 & 3 & 3 & 4 \\
\hline 36 & K36 & 3 & 2 & 2 & 3 & 4 \\
\hline 37 & K37 & 4 & 2 & 2 & 2 & 2 \\
\hline 38 & K38 & 3 & 4 & 3 & 4 & 3 \\
\hline
\end{tabular}

Sumber: PT Clariant Adsorbents Indonesia

Tabel 4. Keterangan Kriteria Penilaian

\begin{tabular}{ll}
\hline P1 & Kualitas Pekerjaan \\
P2 & Tanggung Jawab \\
P3 & Kerjasama \\
P4 & Kehadiran \\
P5 & Disiplin \\
\hline
\end{tabular}

Tabel 5. Master Data Penilaian

\begin{tabular}{ll}
\hline & \multicolumn{1}{c}{ Nilai } \\
\hline 1 & Unsatisfactory \\
2 & Needs Improvement \\
3 & Fully Satosfactory \\
4 & Superior \\
5 & Outstanding \\
\hline
\end{tabular}

1. Menentukan Jumlah Cluster

Pada penelitian ini menetapkan 3 Cluster yang dipilih secara random pada variable kualitas pekerjaan, tanggung jawab, kerjasama, kehadiran dan disiplin. 
ISSN 2614-5278 (media cetak), ISSN 2548-8368 (media online)

Available Online at https://ejurnal.stmik-budidarma.ac.id/index.php/mib

DOI 10.30865/mib.v5i2.2909

Tabel 6. Cluster Awal

\begin{tabular}{cccccc}
\hline \multicolumn{6}{c}{ Initial Centroid } \\
\hline \multirow{2}{*}{ Cluster } & $\begin{array}{c}\text { Kualitas } \\
\text { Pekerjaan }\end{array}$ & $\begin{array}{c}\text { Tanggung } \\
\text { Jawab }\end{array}$ & Kerjasama & Kehadiran & Disiplin \\
\hline C1 & 3 & 2 & 2 & 4 & 3 \\
C2 & 2 & 2 & 2 & 2 & 3 \\
C3 & 4 & 3 & 3 & 2 & 5 \\
\hline
\end{tabular}

2. Menghitung Jarak untuk setiap data ke pusat Dari data ke-1 ke pusat cluster 3luster

Penelitian ini menggunakan pengukuran jarak pada ruang jarak ( distance space) Euclidean dengan menggunakan rumus :

$$
\begin{aligned}
D_{l_{2}}\left(x_{2}, x_{1}\right) & =\left\|X_{2}-X_{1}\right\|^{2} \\
& =\sqrt{\left(x_{21}-x_{11}\right)^{2}+\left(x_{22}-x_{12}\right)^{2}+\left(x_{23}-x_{13}\right)^{2}+\left(x_{24}-x_{14}\right)^{2}}
\end{aligned}
$$

Karena variabelnya ada 5, maka perhitungan $\mathrm{x}$ dilakukan sebanyak 5 kali sebagai perhitungan masing-masing variabel. Berikut ini merupakan contoh perhitungan jarak pada beberapa data sebagai berikut :

a. Perhitungan Dari data ke-1 ke pusat cluster 1

$$
\begin{aligned}
& d(1,1)=\sqrt{(3-3)^{2}+(2-2)^{2}+(2-2)^{2}+(4-4)^{2}+(3-3)^{2}} \\
& d(1,1)=\sqrt{(0)^{2}+(0)^{2}+(0)^{2}+(0)^{2}+(0)^{2}} \\
& d(1,1)=\sqrt{0} \\
& d(1,1)=0,000
\end{aligned}
$$

Dari hasil perhitungan di atas jarak data ke-1 dengan Cluster ke-1 adalah 0,000

b. Perhitungan Dari data ke-1 ke pusat cluster 2

$$
\begin{aligned}
& d(1,2)=\sqrt{(3-2)^{2}+(2-2)^{2}+(2-2)^{2}+(4-2)^{2}+(3-3)^{2}} \\
& d(1,2)=\sqrt{(1)^{2}+(0)^{2}+(0)^{2}+(2)^{2}+(0)^{2}} \\
& d(1,1)=\sqrt{5} \\
& d(1,1)=2,236
\end{aligned}
$$

Dari hasil perhitungan di atas jarak data ke-1 dengan Cluster ke-2 adalah 2,236

c. Perihitungan Hasil jarak terakhir antara centroid dan pusat clusterDari data ke-1 ke pusat cluster 3

$$
\begin{aligned}
& d(1,3)=\sqrt{(3-4)^{2}+(2-3)^{2}+(2-3)^{2}+(4-2)^{2}+(3-5)^{2}} \\
& d(1,2)=\sqrt{(-1)^{2}+(-1)^{2}+(-1)^{2}+(2)^{2}+(-2)^{2}} \\
& d(1,1)=\sqrt{9} \\
& d(1,1)=3,317
\end{aligned}
$$

Dari hasil perhitungan di atas jarak data ke-1 dengan Cluster ke-3 adalah 3,317

Berdasarkan hasil hitungan data ke-1 maka didapatkan hasil kesimpulan bahwa jarak data ke-1 yang paling dekat adalah pada cluster ke-1. Maka pengguna pertama dimasukan ke dalam kelompok cluster ke-1. Lakukan perhitungan di atas sampai dengan data ke-38 hingga masing-masing data menemukan hasil jarak mana yang terdekat dengan cluster.

3. Menyusun atau Menempatkan Data ke dalam Pusat Cluster Terdekat

Setelah dilakukan perhitungan seperti pada contoh sebelumnya, maka hasil perhitungan selengkapnya dapat dilihat pada tabel 7 .

Tabel 7. Jarak data dengan pusat cluster

\begin{tabular}{cllllc}
\hline No & Nama Karyawan & Jarak ke C1 & Jarak ke C2 & Jarak ke C3 & Cluster \\
\hline 1 & Irvan Pranajaya & 0,000 & 2,236 & 3,317 & 1 \\
2 & Supiyani & 1,000 & 2,449 & 3,162 & 1 \\
3 & Riyanto & 1,000 & 1,414 & 2,828 & 1 \\
4 & Abdul Aziz & 0,000 & 2,236 & 3,317 & 1 \\
\hline
\end{tabular}




\section{JURNAL MEDIA INFORMATIKA BUDIDARMA}

Volume 5, Nomor 2, April 2021, Page 573-582

ISSN 2614-5278 (media cetak), ISSN 2548-8368 (media online)

Available Online at https://ejurnal.stmik-budidarma.ac.id/index.php/mib DOI 10.30865/mib.v5i2.2909

4. Mendapatkan Pusat Cluster Baru

Setelah data dihitung dan ditempatkan pada masing-masing cluster terdekat, maka selanjutnya menghitung kembali data untuk mendapatkan pusat cluster yang baru berdasarkan, yakni berdasarkan nilai rata-rata dari masing-masing variabel, pada masing-masing cluster. Adapun perhitungannya adalah sebagi berikut :

a. Rata-rata kualitas pekerjaan pada cluster 1 :

$$
\begin{aligned}
& =\frac{3+3+3+3+2+\cdots+3+4+2+4+3+5+3+3}{16} \\
& =\frac{47}{16} \\
& =2,9
\end{aligned}
$$

b. Rata-rata tanggung jawab pada cluster 1 :

$$
\begin{aligned}
& =\frac{2+3+2+2+2+\cdots+2+2+3+3+2+2+2+2}{16} \\
& =\frac{35}{16} \\
& =2,2
\end{aligned}
$$

c. Rata-rata kerjasama pada cluster 1 :

$$
\begin{aligned}
& =\frac{2+2+2+\cdots+2+2+1+2+2+2+2+2+2}{16} \\
& =\frac{31}{16} \\
& =1,9
\end{aligned}
$$

d. Rata-rata kehadiran pada cluster 1 :

$$
\begin{aligned}
& =\frac{4+4+3+4+\cdots+3+4+3+5+4+4+2+3+3}{16} \\
& =\frac{58}{16} \\
& =3,6
\end{aligned}
$$

e. Rata-rata disiplin pada cluster 1 :

$$
\begin{aligned}
& =\frac{3+\cdots+4+4+3+5+2+2+2+2+5+2+3+4}{16} \\
& =\frac{50}{16} \\
& =3,1
\end{aligned}
$$

f. Rata-rata kualitas pekerjaan pada cluster 2 :

$$
\begin{aligned}
& =\frac{2+\cdots+1+2+3+3+2+2+1+4+4+3+4}{18} \\
& =\frac{43}{18} \\
& =2,4
\end{aligned}
$$

g. Rata-rata tanggung jawab pada cluster 2 :

$=\frac{2+\cdots+3+2+4+4+2+2+2+2}{18}$

$=\frac{41}{18}$

$=2,3$

h. Rata-rata kerjasama kerja pada cluster 2 :

$$
\begin{aligned}
& =\frac{2+\cdots+3+3+3+3+3+2+3+2}{18} \\
& =\frac{42}{18} \\
& =2,3
\end{aligned}
$$

i. Rata-rata kehadiran pada cluster 2 :

$$
\begin{aligned}
& =\frac{2+2+3+3+2+3+2+3+2+2+2+\cdots+2}{18} \\
& =\frac{40}{18} \\
& =2,2
\end{aligned}
$$

j. Rata-rata disiplin pada cluster 2 :

$$
=\frac{3+2+\cdots+4+1+3+2+2+3+4+2+2+3+2+3+2}{18}
$$


JURNAL MEDIA INFORMATIKA BUDIDARMA

Volume 5, Nomor 2, April 2021, Page 573-582

ISSN 2614-5278 (media cetak), ISSN 2548-8368 (media online)

Available Online at https://ejurnal.stmik-budidarma.ac.id/index.php/mib DOI 10.30865/mib.v5i2.2909

$$
\begin{aligned}
& =\frac{44}{18} \\
& =2,4
\end{aligned}
$$

k. Rata-rata kualitas pekerjaan pada cluster 3 :

$$
\begin{aligned}
& =\frac{4+4+4+3}{4} \\
& =\frac{15}{4} \\
& =3,8
\end{aligned}
$$

1. Rata-rata tanggung jawab pada cluster 3 :

$=\frac{3+4+4+4}{4}$

$=\frac{15}{4}$

$=3,8$

m. Rata-rata kerjasama pada cluster 3 :

$=\frac{3+3+3+3}{4}$

$=\frac{12}{4}$

$=3$

n. Rata-rata kehadiran pada cluster 3 :

$=\frac{2+4+3+4}{4}$

$=\frac{13}{4}$

$=3,3$

o. Rata-rata disiplin pada cluster 3 :

$=\frac{5+4+4+3}{4}$

$=\frac{16}{4}$

$=4$

Maka dapat dihasilkan sebagai berikut:

Tabel 8. Centeroid Baru

\begin{tabular}{cccccc}
\hline \multicolumn{5}{c}{ Centroid Baru Interasi 1 } \\
\hline Cluster & P1 & P2 & P3 & P4 & P5 \\
\hline C1 & 2,9 & 2,2 & 1,9 & 3,6 & 3,1 \\
C2 & 2,4 & 2,3 & 2,3 & 2,2 & 2,4 \\
C3 & 3,8 & 3,8 & 3 & 3,3 & 4 \\
\hline
\end{tabular}

5. Menghitung jarak terakhir dengan pusat cluster yang baru

Ulangi proses perhitungan hingga mendapatkan data dengan pola perhitungan terakhir yang sudah tidak berubah-ubah (seperti yang terdapat pada langkah ke-3)

Tabel 9. Hasil Perhitungan jarak terakhir antara centroid dan pusat cluster

\begin{tabular}{clcccc}
\hline No & Nama Karyawan & Jarak ke C1 & Jarak ke C2 & Jarak ke C3 & Cluster \\
\hline 1 & Irvan Pranajaya & 0,446 & 2,008 & 2,487 & 1 \\
2 & Supiyani & 0,908 & 2,115 & 1,920 & 1 \\
3 & Riyanto & 0,670 & 1,215 & 2,385 & 1 \\
4 & Abdul Aziz & 0,446 & 2,008 & 2,487 & 1 \\
\hline
\end{tabular}

6. Pengukuran Nilai Akurasi

Accuration Rate $=\frac{\text { Jumlah data yang sesuai label aslinya }}{\text { Jumlah data keseluruhan }} \times 100 \%$

Hasil akhir yang diperoleh dari perhitungan data dengan menggunakan metode K-Means sebagi berikut:

a. Data yang ada pada cluster 1 terdapat 16 data, maka nilai akurasinya adalah sebagai berikut :

$$
\text { Accuration Rate }=\frac{16}{38} \times 100 \%=0,42 \%
$$


ISSN 2614-5278 (media cetak), ISSN 2548-8368 (media online)

Available Online at https://ejurnal.stmik-budidarma.ac.id/index.php/mib DOI 10.30865/mib.v5i2.2909

Jadi nilai akurasi pada cluster 1 adalah $0,42 \%$

b. Data yang ada pada cluster 2 terdapat 18 data, maka nilai akurasinya adalah sebagai berikut :

$$
\text { Accuration Rate }=\frac{18}{38} \times 100 \%=0,47 \%
$$

Jadi nilai akurasi pada cluster 2 adalah $0,47 \%$

c. Data yang ada pada cluster 3 terdapat 4 data, maka nilai akurasinya adalah sebagai berikut :

Jadi nilai akurasi pada cluster 3 adalah $0,11 \%$

$$
\text { Accuration Rate }=\frac{4}{38} \times 100 \%=0,11 \%
$$

\section{KESIMPULAN}

Algoritma k-means dapat dijadikan acuan oleh pihak perusahaan untuk mengelompokkan penilaian kinerja berdasarkan variabel biner seperti nilai kualitas kerja, nilai tanggung jawab, nilai kerjasama, nilai kehadiran dan nilai disiplin. Data penialian dikelompokkan menjadi tiga cluster (sangat produktif, cukup produktif dan kurang produktif). Hasil akurasi yang didapatkan setelah dihitung adalah (1) $0,42 \%$ untuk cluster 1 kategori sangat produktif, yang terdiri dari 16 data karyawan (2) 0,47\% untuk cluster 2 kategori cukup produktif, yang terdiri dari 18 data karyawan (3)0,11\% untuk cluster 3 kategori kurang produktif, yang terdiri dari 4 data karyawan. Penelitian ini dibatasi karena hanya menggunakan lima variabel. Sehingga untuk penelitian selanjutnya perlu menambahkan variabel lain dalam mengevaluasi kinerja karyawan agar bisa lebih baik lagi hasilnya serta untuk penelitian selanjutnya dapat dilakukan penelitian dengan cara membandingkan beberapa metode agar hasilnya lebih akurat meskipun dengan permasalahan yang sama, atau bisa juga dengan menggabungkan dua metode atau lebih agar diperoleh hasil yang maksimal dan dapat mencapai tujuan yang diinginkan.

\section{REFERENCES}

[1] S. N. Evita, W. O. Z. Muizu, and R. T. W. Atmojo, "Penilaian Kinerja Karyawan Dengan Menggunakan Metode Behaviorally Anchor Rating Scale dan Management By Objectives (Sudi kasus pada PT Qwords Company International)," Pekbis J., vol. 9, no. 1, pp. 18-32, 2017, [Online]. Available: https://www.neliti.com/id/publications/164390/penilaian-kinerja-karyawan-dengan-menggunakan-metodebehaviorally-anchor-rating.

[2] D. Sartika and J. Jumadi, "Clustering Penilaian Kinerja Dosen Menggunakan Algoritma K-Means (Studi Kasus: Universitas Dehasen Bengkulu)," Sainteks 2019, pp. 703-709, 2019, [Online]. Available: https://seminar-id.com/semnassainteks2019.html.

[3] H. Fadri, Z. Zulfadil, and T. Taufiqurrahman, "Analisis Kinerja Karyawan Pada Pt Perindustrian Dan Perdagangan Bangkinang," J. Online Mhs. Fak. Ekon. Univ. Riau, vol. 4, no. 1, pp. 414-425, 2016, [Online]. Available: https://media.neliti.com/media/publications/121480-ID-analisis-kinerja-karyawan-pada-pt-perind.pdf.

[4] B. M. .\& Daryanto, Manajemen Penilaian Kinerja Karyawan. Malam: Gava Media, 2017.

[5] L. V. Lie, “Analisis Pengaruh Kepuasan Kerja Terhadap Kinerja Karyawan Di Pt.X,” Agora, vol. 5, no. 1, pp. 1-5, 2017, [Online]. Available: http://publication.petra.ac.id/index.php/manajemen-bisnis/article/view/5305.

[6] S. Setiawan, "Analisis Cluster Menggunakan Algoritma K-Means Untuk Mengetahui Kemampuan Pegawai Dibidang It Pada Cv . Roxed Ltd," J. Pelita Inform., vol. 18, pp. 80-86, 2019, [Online]. Available: https://ejurnal.stmikbudidarma.ac.id/index.php/pelita/article/view/1142.

[7] N. Agustina and P. Prihandoko, "Perbandingan Algoritma K-Means dengan Fuzzy C_Means Untuk Clustering Tingkat Kedisiplinan Kinerja Karyawan (Studi Kasus: Sekolah Tinggi Teknologi Bandung)," J. RESTI (Rekayasa Sist. dan Teknol. Informasi), vol. 2, no. 3, pp. 621-626, 2018, doi: 10.29207/resti.v2i3.492.

[8] M. R. L. Iin Parlina, Agus Perdana Windarto, Anjar Wanto, "Memanfaatkan Algoritma K-Means Dalam Menentukan Pegawai Yang Layak Mengikuti Asessment Center," Memanfaatkan Algoritm. K-Means Dalam Menentukan Pegawai Yang Layak Mengikuti Asessment Cent. Untuk Clust. Progr. Sdp, vol. 3, no. 1, pp. 87-93, 2018, [Online]. Available: https://jurnal.unimed.ac.id/2012/index.php/cess/article/view/8192.

[9] D. Imantika et al., "Penerapan metode k-means clustering dan analytical hierarchy process (ahp) untuk pengelompokan kinerja guru dan karyawan pada sma brawijaya smart school," J. Pengemb. Teknol. Inf. dan Ilmu Komput. J-PTIIK, vol. 3, no. 8, pp. 7382-7390, 2019, [Online]. Available: http://j-ptiik.ub.ac.id/index.php/j-ptiik/article/view/5958.

[10] F. A. Hermawati, Data Mining (Putri Christian, ed.). Surabaya: Andi Offset, 2013.

[11] S. Handoko, F. Fauziah, and E. T. E. Handayani, "Implementasi Data Mining Untuk Menentukan Tingkat Penjualan Paket Data Telkomsel Menggunakan Metode K-Means Clustering," J. Ilm. Teknol. dan Rekayasa, vol. 25, no. 1, pp. 7688, 2020, doi: 10.35760/tr.2020.v25i1.2677.

[12] F. Yunita, "Penerapan Data Mining Menggunkan Algoritma K-Means Clustring Pada Penerimaan Mahasiswa Baru (Studi Kasus: Universitas Islam Indragiri)," J. Sist., vol. 7, no. September, pp. 238-249, 2018, [Online]. Available: http://sistemasi.ftik.unisi.ac.id/index.php/stmsi/article/view/388.

[13] F. N. R. F. Aziz, B. D. Setiawan, and I. Arwani, "Implementasi Algoritma K-Means untuk Klasterisasi Kinerja Akademik Mahasiswa," J. Pengemb. Teknol. Inf. dan Ilmu Komput., vol. 2, no. 6, pp. 2243-2251, 2018, [Online]. Available: http://jptiik.ub.ac.id/index.php/j-ptiik/article/view/1571.

[14] R. T. Vulandari, Data Mining (Teori dan Aplikasi Rapidminer). Surakarta: Gava Media, 2017. 
JURNAL MEDIA INFORMATIKA BUDIDARMA

Volume 5, Nomor 2, April 2021, Page 573-582

ISSN 2614-5278 (media cetak), ISSN 2548-8368 (media online)

Available Online at https://ejurnal.stmik-budidarma.ac.id/index.php/mib

DOI 10.30865/mib.v5i2.2909

[15] C. M. Fikri, F. Eka, M. Agustin, and F. Mintarsih, "Pegawai Menggunakan Algoritma K-Means ++ Dan Cop-Kmeans Untuk Merencanakan Program Pemeliharaan Kesehatan Pegawai," J. Pesudocode, vol. IV, pp. 9-17, 2017, [Online]. Available: https://ejournal.unib.ac.id/index.php/pseudocode/article/view/2572.

[16] I. G. B. R. Utama, Statistika Penelitian Bisnis \& Pariwisata. Yogyakarta: Andi, 2018.

[17] E. . Sangadji \& Sofiah, Metodologi Penelitian-Pendekatan Praktis Dalam Penelitian (1 st ed.). Yogyakarta: Andi Offset, 2010 